\title{
So We Think We Can Dance
}

\author{
Myrella Roy
}

$\mathrm{T}$ he Canadian Society of Hospital Pharmacists (CSHP) put on its dancing shoes in 2012 and danced the year away. We, the leadership, volunteers, and staff of the Society, did our best to wow the judges with our fancy footwork, so that CSHP would be acclaimed the leading influence on the advancement of hospital pharmacy practice in Canada. Relive the great moments of CSHP's performance and consider the scores you would award for our visionary steps, namely, equipping pharmacists to practise to their full scope, advocating for the profession, collaborating with critical stakeholders, and fostering engagement and networking among our members.

The problem of drug shortages certainly kept CSHP hip-hopping this past year. We pursued efforts to create a single, national, robust system for monitoring drug shortages, granted interviews to numerous media outlets, launched a dedicated eForum for CSHP members, and testified before the Standing Committee on Health of the House of Commons of Canada during hearings on the role of government and industry in determining drug supply in Canada (www.cshp.ca/advocacy/ CSHPspeaks/drugShortages_e.asp). We performed with our usual partners-BIOTECanada, the Canadian Association of Chain Drug Stores (CACDS), the Canadian Association for Pharmacy Distribution Management (CAPDM), the Canadian Generic Pharmaceutical Association (CGPA), the Canadian Medical Association (CMA), the Canadian Pharmacists Association (CPhA), and Canada's Research-Based Pharmaceutical Companies (Rx\&D) - to hold a workshop on May 28. This workshop, facilitated by GS1 Canada, brought together key stakeholders to identify gaps in the existing systems and processes for monitoring drug shortages, to propose the necessary features of a single national system, and to develop an implementation plan. Rx\&D and CGPA each committed $\$ 100000$ toward the creation of this national system. As an interim step, $\mathrm{Rx} \& \mathrm{D}$ opened its drug shortage reporting platform to CGPA member companies and all other Canadian pharmaceutical manufacturers. Its bilingual platform is now known as the Canadian Drug Shortage Database and is publicly accessible at www.drugshortages.ca. In late July, Health Canada and Alberta Health (the lead of the Provincial/Territorial Task Force on Drug Shortages) cut in and invited CSHP, BIOTECanada,

\section{CACDS, CAPDM, CGPA,}

CMA, CPhA, and Rx\&D to join them, the Canadian Agency for Drugs and Technologies in Health, and the group purchasing organizations HealthPRO and Medbuy in forming the Multi-Stakeholder Steering Committee on Drug Shortages, for collaborative numbers on preventing and mitigating shortages across Canada.

CSHP performed a pas de deux with its British Columbia Branch to raise public awareness of the expected consequences for the health care system of the provincial government's plan to remove a market wage adjustment for hospital pharmacists. The duo also executed an awe-inspiring move, with CSHP lifting the BC Branch's graceful video on the value of hospital pharmacists and carrying it to CSHP Council. The video, now available to all branches (www.cshp.ca/advocacy/index_e.asp), can be used to showcase hospital pharmacists to the public, politicians and government officials.

The Canadian Hospital Pharmacy Residency Board waltzed into a reception at the 2012 Professional Practice Conference to celebrate its 50th anniversary. In 1956, Isabel Stauffer proposed that the Canadian Conference of Pharmaceutical Faculties partner with CSHP to establish minimum standards for pharmacy internships in hospitals, and 1962 saw the establishment of the first Residency Board, consisting of Isabel Stauffer, Orest Buchko, Phyllis Yagi, André Archambault, and Glen Moir. You can view a slide presentation recounting key events in the Board's history at www.cshp.ca/programs/ residencyTraining/CHPRBinfo_e.asp.

In addition to its time-honoured research grant competition, the CSHP Foundation choreographed new rock 'n' rolling education grant opportunities. Two competitions were launched in the fall for innovative approaches to professional education, dialogue, and knowledge transfer, to improve the delivery of patient care in hospitals and collaborative health care settings. 
The first competition offers funding for educational programs such as traineeships, thematic conferences, and resources for health care professionals or patients (www.cshpfoundation.ca/ web/la/en/pa/6486eac590b14c21b850e8b8174d2706/ template.asp). The second one will confer a scholarship on a current or aspiring hospital pharmacy leader, to be used for the Pharmacy Leadership Academy of the Research and Education Foundation of the American Society of Health-System Pharmacists, a 12-month distance-learning program designed to enhance leadership performance and to train future leaders in hospital pharmacy (www.cshpfoundation.ca/web/la/en/pa/ 8D2A40F30B8A4883AC11DBA30BD18BBB/template.asp).

CSHP also square-danced with several other national organizations: Accreditation Canada, which sought revisions to its Medication Management Standards and Required Organizational Practices; the Canadian Council for Accreditation of Pharmacy Programs, which called for feedback on the second draft of the Accreditation Standards and Guidelines for the First Professional Degree in Pharmacy Programs; Health Canada, which requested comments on the proposed New Classes of Practitioners Regulations, intended to designate midwives, nurse practitioners, and podiatrists as practitioners under the Controlled Drugs and Substances Act, and on the accompanying Regulatory Impact Analysis Statement, and the National Association of Pharmacy Regulatory Authorities (NAPRA), which asked for responses to the draft report entitled Pharmacy Practice Management Systems: Requirements to Support NAPRA Standards of Practice and to the proposed supplemental competency on injection for Canadian pharmacists.

CSHP was also swept up by colourful mariachi rhythms and sensual tango music. As CSHP Executive Director, I gave a presentation on the role of hospital pharmacists in interprofessional care in Canada at the Second Hospital Pharmacy Congress of the Mexican Association of Hospital Pharmacists in Puebla, Mexico, in June. Then, in November, I gave a similar talk at the First South American Congress of Hospital Pharmacy, organized by the Argentinean Association of Hospital Pharmacists, in Mar del Plata, Argentina.
Many more collective achievements kept CSHP staff members on their toes. The Pharmacy Specialty Networks were relocated from the Yahoo! Groups platform to CSHP's association management system. The Society's electronic mailing lists, known as eForums, now interface directly with the membership database and are located on the CSHP website. For the second year, CSHP joined forces with the Organizing Committee of the Harrison Pharmacy Conference to hold the 21st education and networking event for hospital pharmacy leaders, now known as the CSHP Harrison Pharmacy Management Seminar (www.harrisonconference.ca). We added two publications to our library: Medication Incidents: Guidelines on Reporting and Prevention, revised by the Practice Standards Steering Committee, and the Evidence-Based Clinical Guidelines for Immigrants and Refugees, prepared by the Canadian Collaboration for Immigrant and Refugee Health and endorsed by CSHP Council. The CSHP e-Newsbrief was also launched in April; this weekly newsletter aggregates the latest headline news, research findings, and other online articles that matter to hospital pharmacists.

CSHP saw a few changes to its dance company over the past year. We bade farewell to Amanda Cuirrier as Interim Membership and Awards Administrator and welcomed Cheryl Mallory to take on this position. We also greeted Pamela Saunders, who entered the troupe as Interim Office Administrator (including responsibility for CSHP 2015 and the Board of Fellows).

I hope that you are impressed by CSHP's performance in 2012 and that we have earned your vote as the leading influence on the advancement of hospital pharmacy practice in Canada. Put your best foot forward as a volunteer and join us on the dance floor!

Myrella Roy, BScPhm, PharmD, FCCP, is Executive Director of the CSHP. 